\title{
Differences in Associated Crustacean Fauna and Seasonality of Sexual Reproduction between Two Color Morphs of the Photosymbiotic Ascidian Didemnum molle (Ascidiacea: Didemnidae) ${ }^{1}$
}

\author{
Takumi Fukuda ${ }^{2}$ and Euichi Hirose ${ }^{2,3}$
}

\begin{abstract}
Photosymbiotic ascidians inhabiting subtropical waters tend to have gonads in spring and summer, whereas those in tropical waters are usually sexually mature year-round. We studied the seasonality of sexual reproduction in two populations of the photosymbiotic ascidian Didemnum molle (Herdman, 1886), sampling monthly for 12 months. Although the two populations were located only about $20 \mathrm{~km}$ apart, their color morphs were exclusively distributed: colonies of one population were always dark gray; those of the other population were mostly brown. The seasonality of sexual reproduction differed greatly between the populations (and thus between the color morphs). Sexual reproduction was limited to summer in the population with dark gray colonies, whereas the population with brown colonies possessed embryos with tails almost yearround. Moreover, the resident crustacean fauna in the colonies also differed between the populations. The microenvironment in each habitat may have caused these differences, but there may also be some physiological differences between the color morphs that affect the seasonality of sexual reproduction and the resident crustacean fauna.
\end{abstract}

Didemnum molle (Herdman, 1886) is a colonial ascidian that always harbors prokaryotic photosymbionts, Procbloron spp., on the inner surface of the large cloacal cavity. The colonies are common throughout the Indo-West Pacific Ocean, ranging from almost $30^{\circ} \mathrm{N}$ to $30^{\circ} \mathrm{S}$ (Kott 2001). Although the domeshaped colonies are conspicuous in shallow reefs, they are often found below $30 \mathrm{~m}$ in depth. The range of $D$. molle is much larger than that of other photosymbiotic species, indicating the high adaptability of the species to various environmental factors such as temper-

${ }^{1}$ This study was supported by the 21 st Century Center of Excellence (COE) Program of the University of the Ryukyus. Manuscript accepted 15 August 2007.

${ }^{2}$ Department of Chemistry, Biology, and Marine Science, Faculty of Science, University of the Ryukyus, Nishihara, Okinawa 903-0213, Japan. .ac.jp).

${ }^{3}$ Corresponding author: (e-mail: euichi@sci.u-ryukyu

Pacific Science (2008), vol. 62, no. 3:309-316

(C) 2008 by University of Hawai'i Press

All rights reserved ature and light intensity. For instance, the content of ultraviolet (UV)-absorbing substances in colonies decreases with increasing depth from 10 to $20 \mathrm{~m}$ (Hirose et al. 2006b). Because light conditions are critical not only for the ascidian zooids but also for the photosymbionts, the adjustment in UV protection in D. molle may play an important role in its survival over a wide range of latitudes and depths.

Seasonal variation in water temperatures may affect the sexual reproduction of photosymbiotic ascidians, although there have been few studies based on periodic sampling. For instance, colonies of D. molle (Olson 1983) and Trididemnum solidum (van Duyl et al. 1981) appear to spawn larvae year-round in tropical waters, in which the temperature is almost constant, whereas monthly surveys show that colonies of Diplosoma virens, Lissoclinum bistratum, and T. cyclops in subtropical coral reefs, in which the water temperature varies from about $20^{\circ} \mathrm{C}$ to $30^{\circ} \mathrm{C}$ during the year, have gonads only in spring and summer (Hirose et al. 2005, 2006a) or summer to autumn (Hirose et al. 2007). Although there are no records of periodic sampling for these 
three species in tropical waters, irregularly sampled colonies have larvae in both summer and winter (cf. Kott 2001). Although D. molle is common in both tropical and subtropical waters, it is not clear whether this species shows seasonal sexual reproduction in subtropical waters.

Various color morphs occur in D. molle: white, white with brown and/or gray patches, brown, and dark gray. These colony colors are determined by calcareous spicules (white) and pigment cells (brown and dark gray) distributed beneath the colony surface. Although Olson (1983) suggested that the color morphs might be different species, they are currently regarded as a single species by taxonomists (cf. Monniot and Monniot 1996, Kott 2001). In patchy colonies, the coloration and area of patches are so variable among the colonies that it is difficult to classify them into discrete color morphs. In contrast, brown and dark gray colonies are almost entirely monochromatic and are easily discriminated from other color morphs. In shallow reef lagoons off Okinawa Island (Ryukyu Archipelago, Japan), populations of D. molle mainly consist of brown colonies at Seragaki, whereas only gray colonies are found at Bise. Although the two populations are distributed at similar depths $(0.5-1 \mathrm{~m})$ and are located only about $20 \mathrm{~km}$ apart, the contents of photosymbionts and UV-absorbing substances in dark gray colonies are significantly greater than those in brown colonies (Hirabayashi et al. 2006). Therefore, the dark gray colonies of $D$. molle appear to differ physiologically from the brown colonies, and this difference may affect other activities of the host animals, such as sexual reproduction. Further comparisons between these color morphs will provide valuable information on the physiological and taxonomic relevance of the color morphs of D. molle and other photosymbiotic benthos in shallow reefs. Here, we report the seasonality of sexual reproduction in the two populations of $D$. molle (the dark gray and brown colonies), on the basis of monthly sampling. We also describe the occurrence of some parasitic or commensal copepods and a shrimp inhabiting the cloacal cavity of the ascidian colonies.

\section{MATERIALS AND METHODS}

Didemnum molle colonies $>1 \mathrm{~cm}$ on the major axis were collected from the shallow reef lagoons off Bise $\left(26^{\circ} 42^{\prime} 30^{\prime \prime} \mathrm{N}, 127^{\circ} 52^{\prime} 45^{\prime \prime}\right.$ $\mathrm{E}$; approximately $0.5 \mathrm{~m}$ in depth) and Seragaki $\left(26^{\circ} 30^{\prime} 30^{\prime \prime} \mathrm{N}, 127^{\circ} 51^{\prime} 50^{\prime \prime} \mathrm{E}\right.$; $<1 \mathrm{~m}$ in depth), Okinawa Island, Ryukyu Archipelago, Japan. Monthly sampling by hand was carried out from September 2003 to August 2004 for the Bise population (dark gray colonies) and from August 2004 to July 2005 for the Seragaki population (brown colonies). The colonies were immediately taken to the laboratory and fixed with $10 \%$ formalin-seawater after anesthesia with menthol and magnesium chloride $\left(\mathrm{MgCl}_{2}\right)$.

Fixed colonies were dissected under a stereomicroscope to determine the presence or absence of testes, eggs, and embryos. Because it was difficult to distinguish between eggs and early embryos, they were combined into a single category. Embryos with tails, if present, were also recorded. More than 10 zooids in each of 10 colonies were examined each month. When a single zooid possessed a testis (or egg), the whole colony was recorded as being sexually mature. Commensal or parasitic copepods and shrimp were sometimes found in the cloacal cavities of the colonies. We recorded their numbers for each colony. Water temperature data from coastal observations at Sesoko Station $\left(26^{\circ} 38^{\prime} 8^{\prime \prime} \mathrm{N}, 127^{\circ}\right.$ $\left.51^{\prime} 55^{\prime \prime} \mathrm{E}\right)$ were kindly provided by the Tropical Biosphere Research Center, University of the Ryukyus, Japan.

\section{RESULTS}

\section{Copepods and a Shrimp in the Common Cloacal Cavity}

Copepods and a palaemonid shrimp occasionally inhabited the common cloacal cavity of the colonies (Figure 1). Although we could distinguish three types of copepods, we could not identify them taxonomically; thus, we designated them as copepods A, B, and C. The palaemonid shrimp was identified as Periclimenaeus sp. Although the colonies at Bise harbored only copepod A, all three types of copepods and Periclimenaeus sp. were 

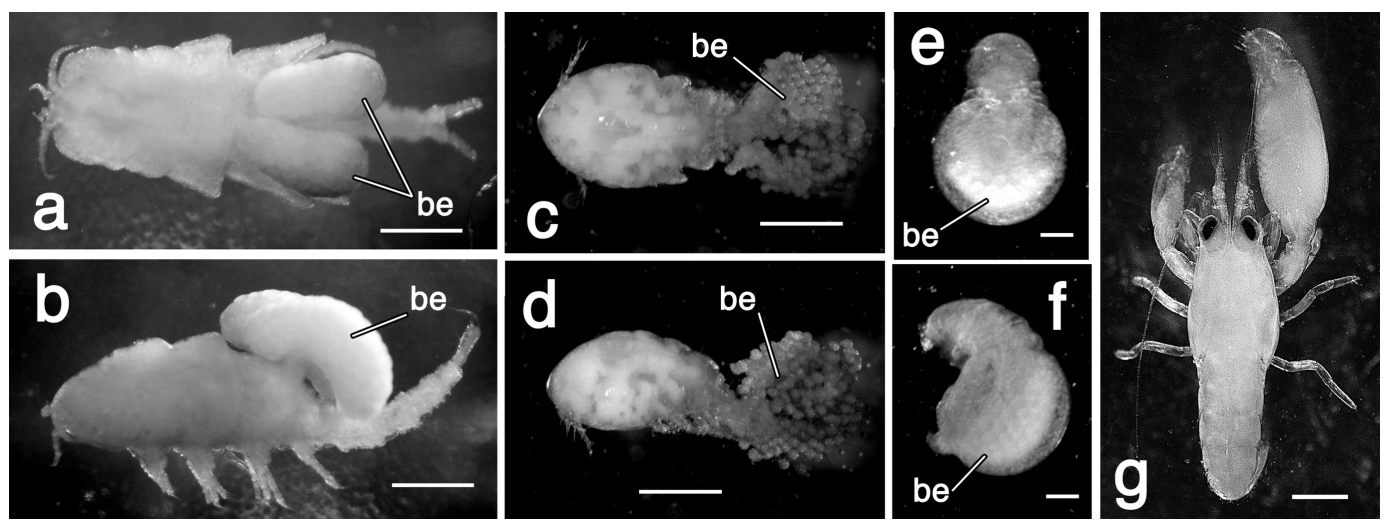

Figure 1. Parasitic or commensal copepods and a shrimp from colonies of Didemnum molle. Shown are copepod A ( $a$, dorsal view; $b$, lateral view), copepod B ( $c$, dorsal view; $d$, lateral view), copepod C ( $e$, ventral view; $f$, lateral view), and Periclimenaeus sp. ( $g$, dorsal view). be, brooded embryos. Scale bars: $0.5 \mathrm{~mm}(a-d), 0.1 \mathrm{~mm}(e$ and $f), 1 \mathrm{~mm}(g)$.

found in the colonies at Seragaki. Periclimenaeus sp. usually inhabited a large colony in the population. Specimens of these resident crustaceans were deposited in the Nagoya University Museum (NUM): copepod A, NUMAz-0546; copepod B, Num-Az-0547; copepod C, num-Az-0548; Periclimenaeus sp., Num-Az0549 .

\section{Bise Population}

All colonies in the Bise population were entirely dark gray. Colonies with testes were observed in spring and summer (MaySeptember), and those with eggs or early embryos were observed in July and August (Figure $2 A$ ). Embryos with tails were mainly observed in July and to some degree in August but not in any other month (Figure $2 B$ ).

Copepod A was found throughout the year, except in September, October, January, and February, and was abundant in July and August (Figure $2 C$ ). The colonies harboring the copepods often contained ascidian embryos with tails in August. Many of the copepods brooded their own embryos. In the 120 colonies examined thus far, copepod A was found in 17 colonies that contained ascidian eggs and/or embryos. Neither copepod B nor $\mathrm{C}$ was found in colonies of the Bise population.

\section{Seragaki Population}

All colonies in the Seragaki population were entirely or mostly brown; none was entirely dark gray. Colonies with testes were found year-round, and those with eggs or early embryos were observed throughout the year, except in March (Figure $3 A$ ). Moreover, embryos with tails were also found throughout the year, except in February and March (Figure $3 B$ ).

Parasitic or commensal crustaceans were always found. Copepod $\mathrm{C}$ was found throughout the year, except in September, and Periclimenaeus sp. was found from April to June and in September (Figure $3 C$ and $D$ ). In addition, small numbers of copepod A were observed in March and May, and copepod B was observed only in August. More than threefourths of specimens of copepod $\mathrm{C}$ had eggs or embryos (Figure $3 C$ ). In the 120 colonies examined thus far, crustaceans were found in 53 colonies, two of which harbored more than one species. One colony harbored one copepod $\mathrm{A}$ and 10 copepod $\mathrm{C}$ specimens, and the other colony had three copepod A specimens and one Periclimenaeus sp. specimen. We found 14 copepod $\mathrm{C}$ specimens in one colony. The ascidian zooids possessed testes in 39 of the 47 colonies that harbored copepod C; 28 of these 39 colonies also contained 

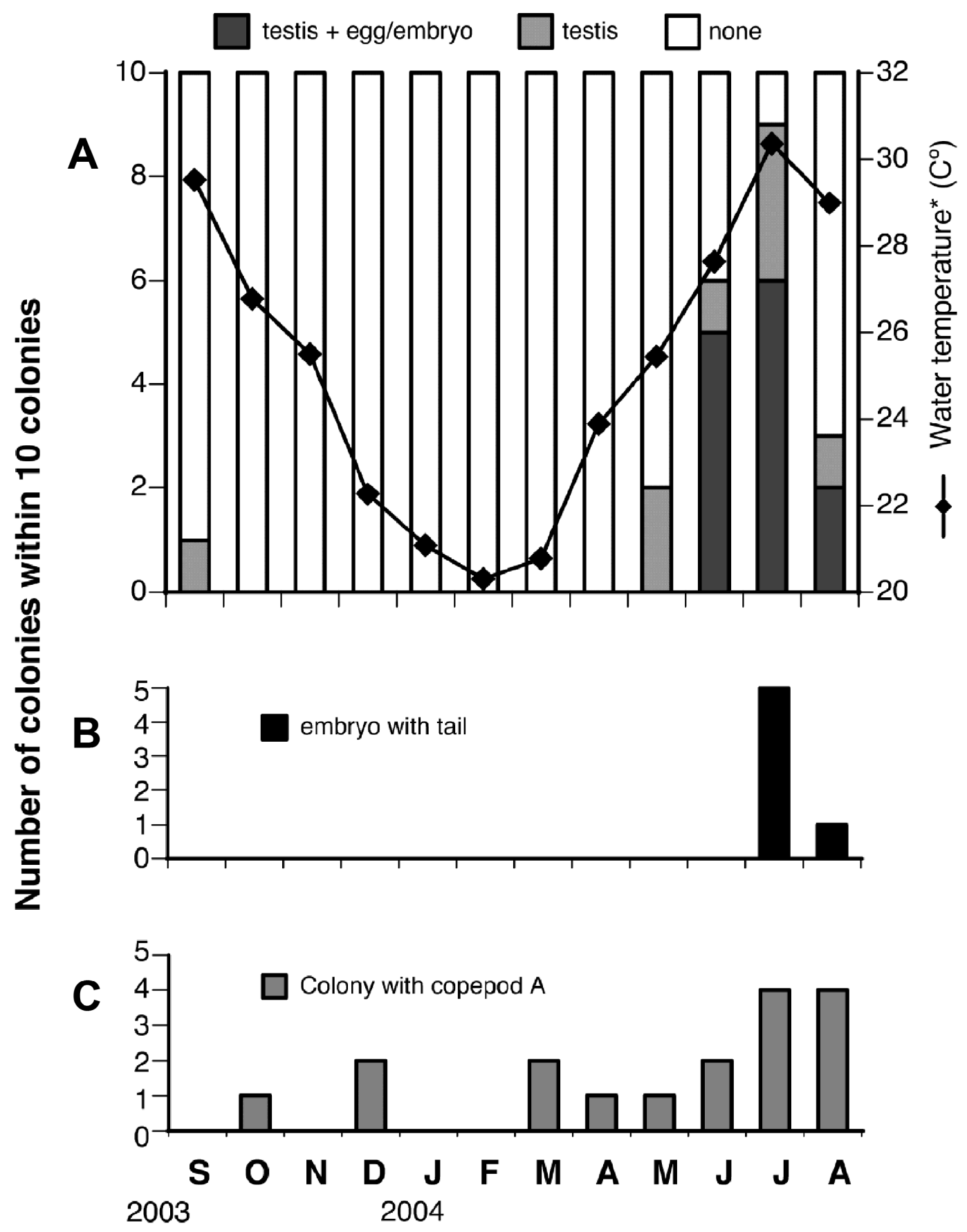

FIGURE 2. Seasonal fluctuations in sexual reproduction in the population at Bise $(A, B)$ and the occurrence of parasitic or commensal copepods $(C)$. Each bar shows the number of the 10 colonies examined each month that possessed gonads or embryos or were associated with copepods. *Temperature data are from coastal observations at Sesoko Station ( $\left.26^{\circ} 38^{\prime} 8^{\prime \prime} \mathrm{N}, 127^{\circ} 51^{\prime} 55^{\prime \prime} \mathrm{E}\right)$, provided by the Tropical Biosphere Research Center, University of the Ryukyus, Japan. 


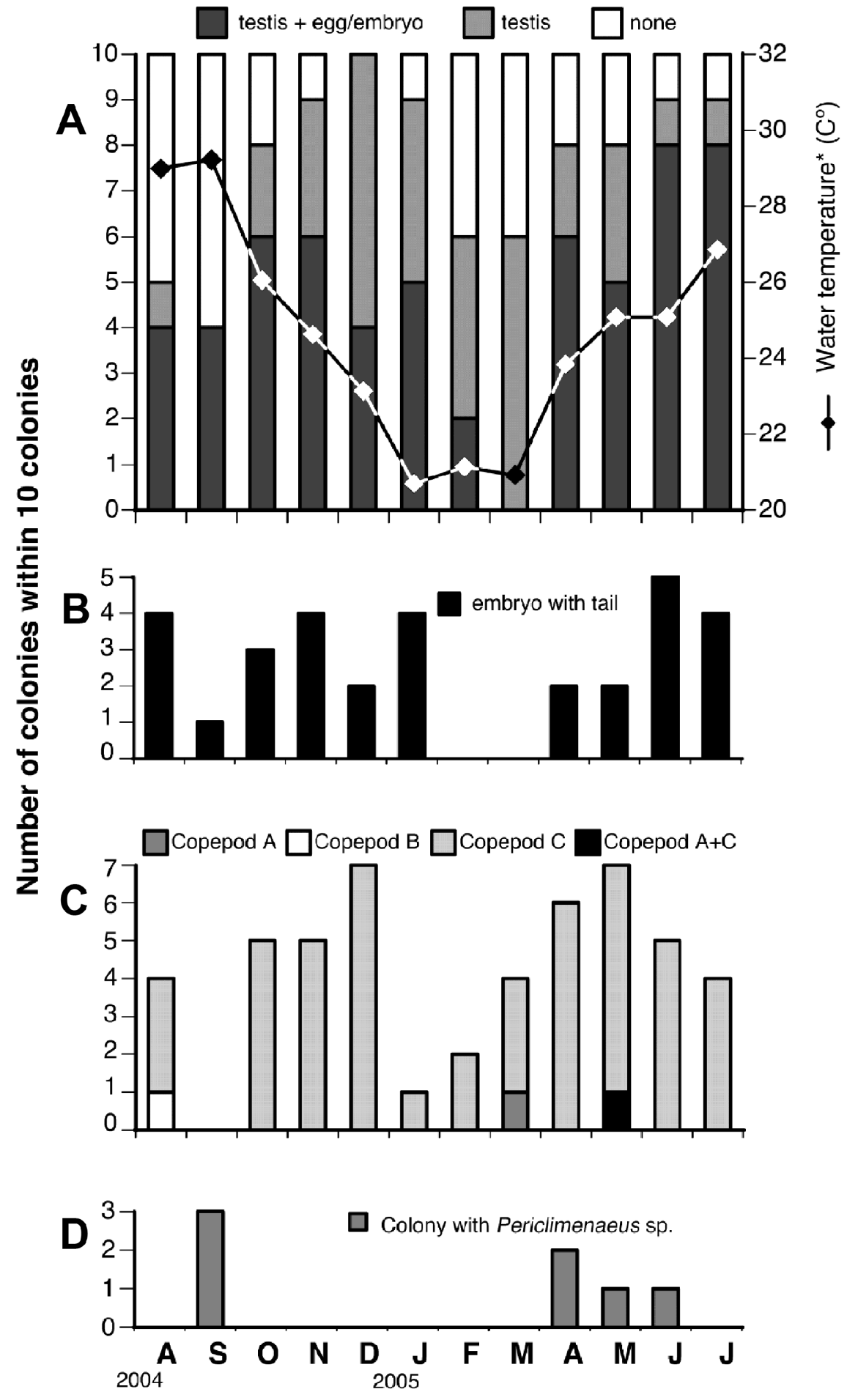

FIGURE 3. Seasonal fluctuations in sexual reproduction in the population at Seragaki $(A, B)$ and the occurrence of parasitic or commensal copepods $(C)$ and a palaemonid shrimp $(D)$. Each bar indicates the number of the 10 colonies examined each month that possessed gonads or embryos or were associated with copepods and the shrimp. *Temperature data are from coastal observations at Sesoko Station $\left(26^{\circ} 38^{\prime} 8^{\prime \prime} \mathrm{N}, 127^{\circ} 51^{\prime} 55^{\prime \prime} \mathrm{E}\right)$, provided by the Tropical Biosphere Research Center, University of the Ryukyus, Japan. 
ascidian eggs and/or embryos. The palaemonid shrimp was always solitary, and some of them brooded their own embryos.

\section{DISCUSSION}

The populations of Didemnum molle at Bise and Seragaki were located only about $20 \mathrm{~km}$ apart, but the seasonality of their sexual reproduction differed greatly. Sexual reproduction was limited to the summer in the Bise population, whereas the colonies at Seragaki had embryos with tails almost year-round, except in February and March (the cold months). The microenvironment at each habitat probably caused this difference, but there may also be some physiological differences between the color morphs of the D. molle colonies.

In photosymbiotic didemnids inhabiting the tropics, sexual reproduction is thought to occur year-round, on the basis of periodic sampling (van Duyl et al. 1981, Olson 1983) and irregular sampling (cf. Kott 2001). In contrast, year-round sexual reproduction of photosymbiotic didemnids has never been reported in the Ryukyu Archipelago, which is situated near the northern limit of the range of coral reefs in the West Pacific. Our previous surveys based on monthly sampling showed that sexual reproduction is limited to the warm season (spring, summer, and/or autumn) in subtropical waters, in which the seasonal variation in water temperature is much greater than in tropical waters (Hirose et al. 2005, 2006a, 2007). However, we found that some colonies in the Seragaki population had gonads even in winter, indicating the possible occurrence of year-round sexual reproduction. On the other hand, embryos with tails were not found in February and March, even in the Seragaki population. This may be consistent with the hypothesis that the low water temperature in subtropical winter (about $20^{\circ} \mathrm{C}$ ) suppresses sexual reproduction in photosymbiotic didemnids (Hirose et al. 2005, 2006a). Although water temperature may be a major factor affecting the seasonal fluctuation in sexual reproduction, it is difficult to explain the remarkable difference in this seasonality between these two populations of D. molle located only $20 \mathrm{~km}$ apart.

There are several color morphs of $D$. molle; some are occasionally suggested to be different species (Olson 1983), although taxonomists usually regard them as a single species (cf. Monniot and Monniot 1996, Kott 2001). In the Bise population, colonies were always entirely dark gray; we found no colonies with brown patches. In contrast, colonies in the Seragaki population were mostly brown. There were no intermediate color morphs at either site. Although the collection site of the brown colonies at Seragaki was slightly deeper than that of the dark gray colonies at Bise, the dark gray colonies were never found in shallow sites at Seragaki. Therefore, the colonies of one color morph do not appear to develop into the other morph, and the color morphs may be defined genetically. Some physiological differences probably occur between the two color morphs: the dark gray colonies at Bise contain significantly greater amounts of photosymbionts and UV-absorbing substances than the brown colonies at Seragaki (Hirabayashi et al. 2006). The remarkable difference in the seasonality of sexual reproduction may reflect physiological differences between the two color morphs.

Copepod A was the only parasitic or commensal copepod inhabiting the common cloacal cavity of the dark gray colonies at Bise. In the brown colonies at Seragaki, most of the parasitic or commensal copepods were copepod C; copepods A and B were uncommon. The palaemonid shrimp Periclimenaeus sp. was occasionally found in colonies at Seragaki but never at Bise. These differences in the resident crustaceans indicate differences in the microenvironment of the cloacal cavity between the colonies of the two sites and/or the two color morphs.

In the photosymbiotic didemnid Diplosoma virens, sexual reproduction appeared to be suppressed when the colonies were severely parasitized by the notodelphyid copepod Loboixys ryukyuensis (Hirose et al. 2005, cf. Ooishi 2006). However, we found parasitic or commensal crustaceans in colonies brooding embryos with tails, and up to 14 copepods 
were found in a single colony. It appears that the resident crustaceans do not markedly suppress the sexual reproduction of the host colony in D. molle. Although the rate of parasitism or commensalism varied among the months, the crustaceans often brooded eggs regardless of the month; they were reproductive throughout the year. Although four crustacean species were found in the Seragaki population, multiple species rarely inhabited a single colony, suggesting the occurrence of interspecific competition within the host colony.

We found remarkable differences in the seasonality of sexual reproduction and the resident crustacean fauna between dark gray and brown colonies that were distributed exclusively at different sites. The colony color of $D$. molle is highly variable because of the differing proportions of spicules, pigment cells, and photosymbionts (cf. Monniot and Monniot 1996, Kott 2001). We could not conclude whether the two color morphs were the same species or discrete species, as suggested by Olson (1983). Although parasitic or commensal organisms are often considered to be host specific, the occurrence of copepod A in both of the color morphs may support the view that these morphs are the same species; however, the occurrence of other crustaceans in only the brown colonies appears to support the view that the color morphs are discrete species. To clarify this problem, a taxonomic survey based on the molecular phylogeny of several color morphs from various sites is required. Recently, molecular evidence revealed potential cryptic species in various ascidian species (e.g., Ciona intestinalis [Suzuki et al. 2005], Clavelina [Tarjuelo et al. 2001], Cystodytes [López-Legentil and Turon 2005, 2006], and Pseudodistoma [Tarjuelo et al. 2004]). Currently, it seems best to regard these color morphs as the same species, because no morphological and/or molecular differences are so far known between the color morphs. The differences between the color morphs discussed here are supposed to be due to the differences of microenvironments of their habitat. According to this view, the colonies of $D$. molle exhibit large variation in colony color, content of photosymbionts and/or UV-absorbing substances, and seasonality of sexual reproduction, which may allow this species to inhabit a wide range of latitudes and depths.

\section{ACKNOWLEDGMENTS}

We are indebted to Yoshihisa Fujita (NPO Marine Learning Center) for the identification of the palaemonid shrimp. We also thank Y. Nakano (Sesoko Station, Tropical Biosphere Research Center) for providing the temperature data.

\section{Literature Cited}

Hirabayashi, S., F. Kasai, M. M. Watanabe, and E. Hirose. 2006. Contents of ultraviolet-absorbing substances in two color morphs of the photosymbiotic ascidian Didemnum molle. Hydrobiologia 571:419422.

Hirose, E., R. Adachi, and K. Kuze. $2006 a$. Sexual reproduction of the Prochloronbearing ascidians Trididemnum cyclops and Lissoclinum bistratum in subtropical waters: Seasonality and vertical transmission of photosymbionts. J. Mar. Biol. Assoc. U.K. 86:175-179.

Hirose, E., S. Hirabayashi, K. Hori, F. Kasai, and M. M. Watanabe. 2006b. UV protection in the photosymbiotic ascidian Didemnum molle inhabiting different depths. Zool. Sci. (Tokyo) 23:57-63.

Hirose, E., A. Kojima, J. Nogami, and K. Teruya. 2007. Seasonality of sexual reproduction in three photosymbiotic Trididemnum species (Didemnidae, Ascidiacea, Tunicata) in a subtropical seagrass bed. J. Mar. Biol. Assoc. U.K. 87:979-982.

Hirose, E., A. T. Oka, and M. Akahori. 2005. Sexual reproduction of the photosymbiotic ascidian Diplosoma virens in the Ryukyu Archipelago, Japan: Vertical transmission, seasonal change, and possible impact of parasitic copepods. Mar. Biol. (Berl.) 146:677-682.

Kott, P. 2001. The Australian Ascidiacea. Part 4, Aplousobranchia (3), Didemnidae. Mem. Queensl. Mus. 47:1-408. 
López-Legentil, S., and X. Turon. 2005. How do morphotypes and chemotypes relate to genotypes? The colonial ascidian Cystodytes (Ascidiacea: Polycitoridae). Zool. Scr. 34:3-14.

2006. Population genetics, phylogeography and speciation of Cystodytes (Ascidiacea) in the western Mediterranean Sea. Biol. J. Linn. Soc. 88:203-214.

Monniot, F., and C. Monniot. 1996. New collections of ascidians from the western Pacific and southeastern Asia. Micronesica 29:133-279.

Olson, R. R. 1983. Ascidian-Prochloron symbiosis: The role of larval photoadaptations in mid-day larval release and settlement. Biol. Bull. (Woods Hole) 165:221-240.

Ooishi, S. 2006. Loboixys ryukyuensis (Crustacea: Copepoda: Cyclopoida: Notodelphyidae), a new genus and species, living in the compound ascidian Diplosoma virens at
Okinawa, Japan. Proc. Biol. Soc. Wash. 119:373-383.

Suzuki, M. M., T. Nishikawa, and A. Bird. 2005. Genomic approaches reveal unexpected genetic divergence within Ciona intestinalis. J. Mol. Evol. 61:627-635.

Tarjuelo, I., D. Posada, K. A. Crandall, M. Pascual, and X. Turon. 2001. Cryptic species of Clavelina (Ascidiacea) in two different habitats: Harbours and rocky littoral zones in the northwestern Mediterranean. Mar. Biol. (Berl.) 139:455-462.

- 2004. Phylogeography and speciation of colour morphs in the colonial ascidian Pseudodistoma crucigaster. Mol. Ecol. 13:3125-3136.

van Duyl, F. C., R. P. M. Bak, and J. Sybesma. 1981. The ecology of the tropical compound ascidian Trididemnum solidum. I. Reproductive strategy and larval behaviour. Mar. Ecol. Prog. Ser. 6:35-42. 